\title{
Combined effect of vital wheat gluten, ascorbic acid and emulsifier addition on the quality characteristics of whole grain barley bread.
}

\author{
Abd-El-Khalek M.H. \\ Food Technology Research Institute, Agricultural Research Center, Giza, Egypt.
}

\begin{abstract}
There is a renewed attention in barley for being used in food products due to its nutritional benefits. Unfortunately barley breads are still inferior in their quality characteristics when compared to their wheat counterparts. The present work studied the individual and interactive effects of three bread improvers (i.e. vital wheat gluten VWG, ascorbic acid AA and sodium stearoyl-2-lactylate SSL) on the quality characteristics of wholegrain barley bread. Results showed significant effects of such improvers on both bread specific volume and overall sensory acceptability. VWG-AA and AASSL interactive effects were positively correlated with bread overall acceptability. Inclusion of bread improvers according to the obtained optimized formula showed a positive effect on bread with regard to its dough rheological properties (longer stability time, lower degree of softening and higher extensibility), physical (specific volume), textural (hardness and springiness), and crumb DIA characteristics of bread. Chemical analysis showed higher nutrient contents (protein, fiber and minerals) in the optimized barley bread when compared to their wheat counterparts. The overall sensory characteristics of the optimized barley bread were acceptable by the panelists with scores corresponded to "like moderately" compared to "extremely like/like very much" in case of wheat bread.
\end{abstract}

Keywords: Barely bread; Gluten; Ascorbic acid; Sodium stearoyl-2-lactylate

\section{Introduction}

Since the cradle of civilizations, barley (Hordeum vulgare L.) has been consumed as a human food. Supported by historical and archeological evidence, barley has been proven for being an important sustaining food grain in many ancient civilizations in wide areas of the world like Egypt, China, Fertile Crescent, Ethiopia, Asia and Europe (Newman and Newman, 2006; Sullivan, Arendt, E. \& Gallagher., 2013; Baik, 2016). Starting from the nineteenth century, consumption of barley as a food has declined due to the abundance and increased consumption of other cereal grain products (with better technological,

\section{*Corresponding author: M. H. Abd-El-Khalek}

Email: mokhtarharb@yahoo.com

Received: September 15, 2020;

Accepted: October 3, 2020;

Published: October 13, 2020. textural and sensory characteristics) like wheat and rice ( Baik and Ullrich, 2008; Langridge, 2018). After corn, wheat and rice, barley becomes the fourth produced cereal grain worldwide with regard to produced quantity (156.08 million metric tons) or cultivated area (51.56 million hectares) in the year 2019/2020 (USDA, 2020). In recent times, approximately two-thirds of cultivated barley has been used as animal feed, one-third in the malting industry and as low as $2-6 \%$ of produced barley is used as a food (Baik and Ullrich, 2008; Baik 2016; Tricase et al., 2018).

Barley has two main advantages, the first is its adaptation to moderate water deficit and thus the ability to thrive under arid and semi-arid areas, and under environmental 
stress in (Newman and Newman, 2008, Carter et al., 2019), and second is its nutrient composition and health benefits. Barley is a good source of protein, dietary fiber (especially soluble $\beta$-glucan), minerals, and phytochemicals such as phenolic acids, phytosterols, flavonoids, lignans, and folate. (Sullivan et al., 2013; Malcolmson et al., 2014; Idehen et al., 2017). Thus, consumption of barley flours was found to be associated with improved health status including normalized blood cholesterol levels and lower risk for coronary heart disease, improved insulin response in diabetics, and better bowel functions (Önning, 2007; Sullivan et al., 2013; Malcolmson et al., 2014; Idehen et al., 2017 ) . The aforementioned advantages are the key drivers for the increasing interest during the last few decades in barley products, especially bakery products (Sullivan et al., 2013; Malcolmson et al., 2014; Baik 2016).

Unfortunately, barley flour alone is not suitable for the production of leavened bakery products such as bread because it lacks the formation of a continuous and elastic gluten network when mixing and kneading with water to form dough. Several attempts have been made to produce leavened bread from barley. Most of studies focused on the partial replacement of wheat flour with barley one (Swanson and Penfield, 1988; Dhingra and Jood, 2001; Holtekjølen et al., 2008; Škrbić et al., 2009; Al-Attabi et al., 2017, Sheikholeslami et al., 2018). Sullivan et al., (2010) studied the effect of using pearled barley flour to replace from 20 to up to $100 \%$ of wheat flour in the production of pan bread. Full replacement with barley flour almost led to a significant reduction in all physical and sensory quality characteristics of bread. Another distinguished study was conducted by Kinner et al. (2011) with the aim of using naked barley flour (excluding bran and shorts) with sufficient $\beta$-glucan content in pure barley bread production. They used an optimization study on different parameters including processing conditions and formula ingredients to obtain acceptable barley bread. In addition, an important study was conducted by Pojić et al., (2017) who studied the feasibility of producing pure barley bread by using three additives (i.e. pregelatinized octenylsuccinic anhydride (OSA) starch, wheat gluten and xylanase) to improve the quality characteristics of produced bread.

Due to the focus on healthier lifestyle and eating patterns, whole grain breads have come to be one of the top preferences for many consumers (Teuber et al., 2016). In many cases, the quality characteristics of whole grain are being less than their (white) flour- or breads made from refined grain flours and thus might not be appealing. These inferior characteristics include for example: low loaf volume, hard and coarse texture, darker color and distinctive flavor (Tebben et al., 2018). As a result, food technologists seek to maintain an acceptable quality of such breads by using a number of bread improvers which include for examples: vital wheat gluten, ascorbic acid, emulsifiers, enzymes, hydrocolloids ... etc. Inclusion of these improvers has a significant enhancement on the physical properties, sensorial acceptability and quality characteristics of whole grain breads in general (Tebben et al.,2018; Sheikholeslami et al., 2018; Parenti et al., 2020).

Different materials are used to enhance the quality characteristics of bread which are known as "bread improvers". Vital wheat gluten (VWG) is an ingredient which is extracted from wheat flour by using different extraction methods, and is widely used to provide the dough system with a gluten network which contributes by its turn to better rheological and dough mixing properties, and thus an improved bread quality (Ortolan and 
Steel, 2017). Ascorbic acid (AA) is also used in the production of bread. Although it is a reducing agent, it works as an oxidizing agent in the presence of oxygen and ascorbic acid oxidase enzyme and leads to an improvement in dough elastic properties and final bread quality (Sahi, 2014).The emulsifier sodium stearoyl-2-lactylate (SSL) is another bread improver that provides desired functions in bread processing including dough strengthening and softer bread crumb (Stampfli and Nersten 1995, Tebben et al.,2018).

The present work was carried out to study the combined effect of using vital wheat gluten, ascorbic acid (as a dough oxidizing agent) and stearoyl-2-lactylate (as an emulsifier) on the chemical, physical and sensory properties of pan bread produced from hull-less whole grain barley flour. Optimized formula was obtained based on bread specific volume and overall acceptability (phase 1 of the study), then it was subjected to comparative study with their whole grain wheat and barley counterparts.

\section{Materials and Methods}

\subsection{Materials:}

The materials used in this study and their sources were as the following:

Hull-less barley (Hordeum vulgare L. var. nudum, cv.Giza 131) was obtained from Field Crop Research Institute (FCRI), Giza, Egypt. Whole grain wheat flour was purchased from KingM Co., Badr City, Egypt. Instant active dry yeast, shortening, skim milk powder, salt and sugar were purchased from a local market in Cairo, Egypt. Ascorbic acid (AA) was obtained from Jaffan Group for Food Solutions, Heliopolis, Cairo. Vital wheat gluten (VWG) and sodium stearoyl-2-lactylate
(SSL) were provided by Food Technology Research Institute (FTRI), Giza, Egypt.

\subsection{Methods:}

\subsubsection{Preparation of barley flour:}

Hull-less barley grains were cleaned manually over a large sieve to remove smaller particles and impurities, milled twice in a Retsch rotor mill (type SK100, Retsch, Germany) to pass through 60 mesh $(0.250 \mathrm{~mm})$ sieve.

\subsubsection{Experimental plan:}

In the present study, the combined effect of VWG, AA and SSL on the quality of whole grain barley bread was investigated in two phases as following:

Phase I included the optimization process to obtain the best levels of (VWG, AA and SSL) with regard to the specific volume and overall acceptability of produced whole grain barley bread, while Phase II included comparison of the optimized whole grain barley bread with that bread made of whole grain wheat or barley counterparts in regard to chemical, physical, Texture Profile Analysis (TPA), crumb Digital Image Analysis (DIA) and sensory properties. A summary of experimental plan is shown in Fig.1.

\subsubsection{Experimental design:}

Box-Behnken design with three independent variables (i.e. VWG, AA and SSL) and 3 levels of addition was used to study the combined effect of the three independent variables on the specific volume and overall acceptability of bread in Phase I of the study. The levels of each independent variable were as follows:

0-12 g of vital wheat gluten, 0-100 ppm of ascorbic acid and 0 to $1 \%$ of SSL. The experimental design which consisted of fifteen 
runs (including three center points) is shown in Table 1. Experimental design generation (Box-Behnken design) and response surfaces for the combined effects of the independent variables (i.e. VWG, AA, and SSL) on the specific volume and overall acceptability of breads, and the optimization process were performed by using Design-Expert7®

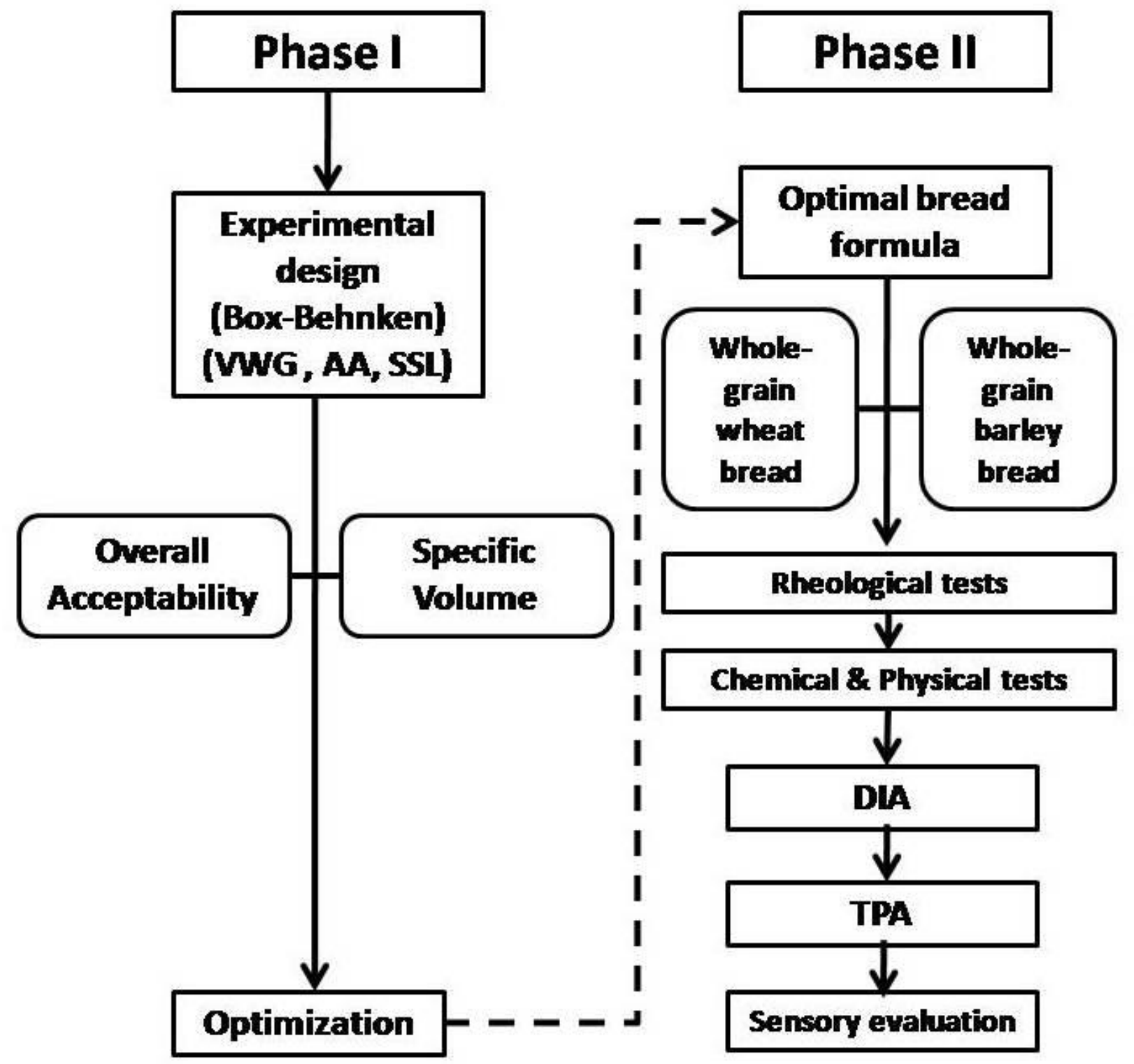

Fig.1. Experimental plan for studying the combined effect of wheat gluten, ascorbic acid and sodium stearoyl-2-lactylate on the quality of whole-grain barley bread. 
a)
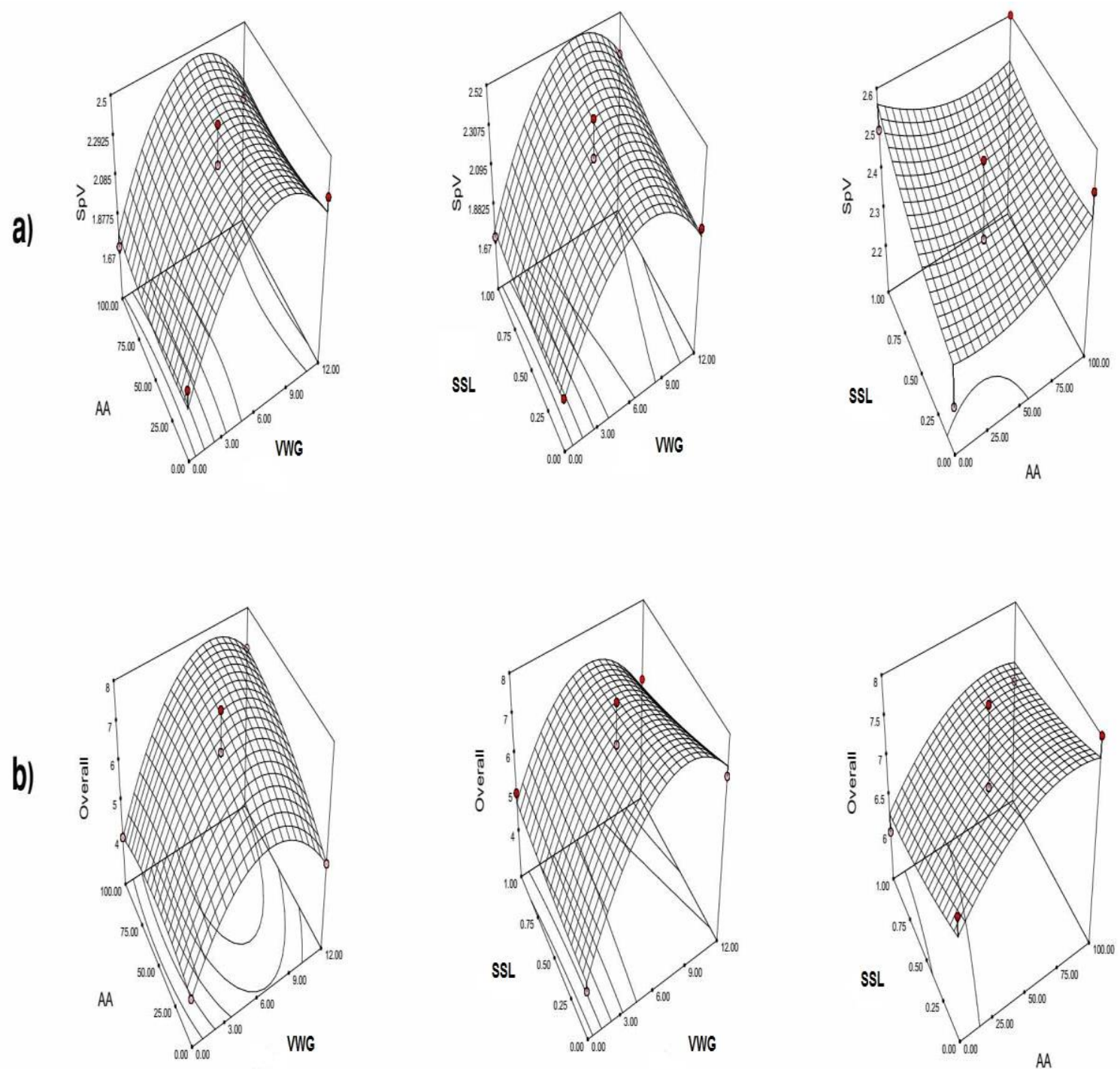

Fig 2. Response surfaces for the combined effect of vital wheat gluten (VWG), ascorbic acid (AA) and sodium stearoyl-2-lactylate (SSL) on the quality characteristics of whole-grain barley bread. A) Effects on specific volume, and B) Effects on overall acceptability.

\subsubsection{Rheological properties:}

\subsubsection{Farinograph test:}

Farinograph instrument (Brabender Duis Bur G, type 810105001 No. 941026 , West Germany) was used to determine the water absorption and mixing characteristics of br ead doughs prepared from whole grain wheat and barley flours. The readings obtained from the farinograms were : arrival time (AT), dough development time (DDT), dough stability time(DST) and degree of softening (DS) , while water absorption (WA) was recorded directly from the farinograph burette as described in the AACC (2010).

\subsubsection{Extensograph test:}

Extensograph test was carried out by using Extensograph (Barabender Duis Bur G type 860001 No. 946003 , West Germany) 
according to the method described in the AACC (2010) to obtain the dough maximum resistance to extension (R, Elasticity), , dough extensibility $(\mathrm{E})$, proportional number $(\mathrm{R} / \mathrm{E})$ and dough energy (E).

\subsubsection{Breadmaking:}

Whole grain pan breads were processed according to the method of AACC (2010). The formulas used for the preparation of bread in both Phases of the study are shown in Table 2. All dry ingredients were mixed well with water until a consistent dough is formed, then they were let to rest for $20 \mathrm{~min}$ at $28-30^{\circ} \mathrm{C}$ (first proofing) followed by dividing doughs into three $150 \mathrm{~g}$ pieces, molded by hand and put into pans $(13 \times 8 \times 7 \mathrm{~cm})$ for final proofing at $32-35^{\circ} \mathrm{C}$ and $80-85 \%$ relative humidity in fermentation cabinet for $60 \mathrm{~min}$. Doughs were then baked in electrically heated oven with steam added during baking at $210-220^{\circ} \mathrm{C}$ for 15 - 20 min. After baking, loaves were separated from the metal pan and allowed to cool at room temperature before being sealed in polyethylene bags to prevent moisture loss and then stored at room temperature (23 \pm $\left.2^{\circ} \mathrm{C}\right)$.

\subsubsection{Proximate chemical composition and Mineral content of breads:}

Proximate chemical composition (moisture, protein, ether extract, ash and dietary fibers) of whole grain breads was determined according to the methods outlined in AACC (2010). Nitrogen Free Extract NFE (carbohydrate) content was calculated by difference.

Mineral content (Ca, P, Mg, Na, K, Fe, Zn and $\mathrm{Cu}$ ) was determined by using Agilent 4200 Microwave Plasma Atomic Emission Spectrometer (Agilent Technologies, Melbourne, Australia) according to the method described by Ozbek and Akman (2016) as follows:

A $20 \mathrm{~g}$ slice of bread was dried in a forced air oven at 100 oC until a constant weight is obtained. Then it was ground and blended by a hand mortar and $1 \mathrm{~g}$ of the ground sample was dissolved in a $3: 1$ mixture of HNO3 $(65 \%$ $\mathrm{w} / \mathrm{v}): \mathrm{H} 2 \mathrm{O} 2(35 \% \mathrm{w} / \mathrm{v})$ and digested at 100 oC for 2 hrs. Digests were then diluted and aspirated to the plasma. Blank samples were prepared by the same procedure.

\subsubsection{Physical, textural and crumb DIA of breads:}

\subsubsection{Bread specific volume:}

For the determination of physical properties, loves were weighed when removed from pans (W), volume (V) was determined by rapeseed displacement method as explained in AACC (2010). Specific volume of bread was calculated in both Phase I and Phase II according to the following equation:

Specific volume $(\mathrm{cm} 3 / \mathrm{g})=\mathrm{V}(\mathrm{cm} 3) / \mathrm{W}(\mathrm{g})$

\subsubsection{Water activity (aw):}

Water activity of breads was measured at room temperature $(25 \mathrm{oC})$ by using a water activity analyzer (Hygrolab, Rotronic AG, Bassersdorf, Switzerland)

\subsubsection{Texture Profile Analysis:}

TPA of bread loaves crumb (Phase II) was assessed by using Brookfield CT3 instrument (Brookfield Engineering Laboratories, Inc., MA 02346-1031, USA) set with a TA-AACC 36 probe as outlined in the AACC (2010) by using the following procedure:

One slice of bread (approximately 25 $\mathrm{mm}$ thickness) was cut from the middle of bread loaves by a sharp hand knife keeping the 
crusts not removed. A 36mm $\varnothing$ TA-AACC36 probe was set at a test speed of $2 \mathrm{~mm} / \mathrm{s}$. Testing was located in the centre of the bread slice avoiding non-representative areas of crumb. Samples were subjected to $40 \%$ deformation and the compression load at $25 \%$. Deformation was recorded in Newtons and the following characteristics were determined: hardness (average of cycle 1 and cycle 2), cohesiveness, adhesiveness, springiness, and chewiness as described in the operating instruction manual.

\subsubsection{Digital Image Analysis (DIA):}

For the assessment of the visual characteristics of whole grain bread crumb samples, digital image analysis (DIA) was conducted according to the method of Magdić et al., (2006) with some modifications as follows:

Bread loaves were sliced in the middle providing two cross sections. Slices were scanned by using CanonScan LIDE100 Scanner (Angioloni and Collar, 2009) and the images were saved with a resolution of 600 dpi. An area of $4 \times 3 \mathrm{~cm}$ was cropped from the middle of the slice for the further assessments. The images were then adjusted and the threshold tool was applied to obtain the binary images by ImageJ ${ }^{\circledR}$ software to differentiate between cells (gas parts) and walls (solid /opaque) areas of bread crumb. The following readings were recorded: cell count, average cell size, and standard deviation (SD) for cell areas.

\subsubsection{Sensory evaluation:}

Sensory characteristics of whole grain bread samples were evaluated by 10 trained panelists. Overall acceptability tests of bread were performed in both Phase I and Phase II of the study, while other characteristics (i.e. appearance, texture, crumb color and flavor) were assessed in Phase II only. A 9-point hedonic scale was used with corresponding values ranging from 1 for "dislike extremely" to 9 for "like extremely" as described by Meilgaard et al., (2016).

\subsubsection{Statistical analysis}

Data obtained from different tests were analyzed by Analysis of Variance using General Linear Model (GLM) procedure within a package program of Statistical Analysis System (SAS, 1999). Means comparison was performed by using Least Significant Difference (L.S.D) test at a degree of significance $(\mathrm{P} \leq 0.05)$.

\section{Results and Discussion}

In order to study the different effects of the three independent variables under investigation (i.e. VWG, AA and SSL) on the quality characteristics of whole grain barley bread, both individual and interactive effects of the aforementioned variables were assessed. Box-Behnken design, with fifteen treatments, was used to study the effect of the three independent variables (with three levels of addition for each) and three center points (which included the middle levels of each variable), on bread specific volume and overall sensory acceptability as determinant quality parameters in Phase I. Optimization process was conducted to determine the best addition level to be used of each independent variable and the produced optimized barley bread formula (Phase II) was subjected to different quality tests as compared to its wheat or barley bread counterparts.

\subsection{Model selection for the effects of VWG, $A A$ and SSL on barley bread quality:}

Summary ANOVA and regression model selection for the different effects of VWG, AA and SSL on specific volume and 
overall acceptability of barley bread are shown in Table 3. The obtained values of bread specific volume (of the fifteen experimental design treatments) ranged from 1.7 to 2.6 with an average of $2.17 \mathrm{~cm} 3 / \mathrm{g}$, while the corresponding values for overall acceptability scores were 4,8 and 6.13 , respectively. Among different regression models suggested by Design-Expert7® Software (linear, quadratic and cubic), and at a probability level of ( $p \leq 0.05)$, second order models (quadratic) were found to best fit, and to be significantly representative to the effects of independent variables (i.e. VWG, AA and SSL) on both specific volume and overall acceptability of

barley bread. The selected models had very high coefficients of determination (R2) of more than 0.9 which could be interpreted as higher proportions of the variance for dependent variables (i.e. bread specific volume and overall acceptability) can be explained by the independent variables (i.e. VWG, AA and SSL) in the obtained regression models. Another determinant measure that explains the good fit of the obtained data to the suggested model is the adjusted-R2 (Anderson and Whitcomb, 2017) which provides a more precise view of the correlation between independent and dependent variables taking into consideration the number of independent variables. The values of adjusted-R2 for both specific volume and overall acceptability models were higher than 0.8 which could represent high quality models. An additional support to the quality of the selected quadratic regression models was the adequate precision ratios. Adequate precision is the signal-to-noise ratio, and it compares the range of the predicted values at the design points to the average prediction error (Anderson and Whitcomb, 2017). The obtained ratios for adequate precision in both models were greater than 4 which are desirable, and thus indicate adequate model discrimination and good representation of the obtained data.

\subsection{Effects of VWG, AA and SSL on bread quality:}

According to the selected quadratic models components, different effects of the independent variables under investigation (i.e, VWG, AA and SSL) on barley bread specific volume and overall sensory acceptability can be explained in the following terms; individual effects of each of the studied independent variables (VWG, AA and SSL) and the interactive (VWG-AA, VWG-SSL and AASSL) effects as shown in Table 4.

\subsubsection{Individual effects of $V W G, A A$ and SSL on bread quality:}

According to the results indicated in Table 4. Specific volume of bread was positively affected by the studied independent variables. VWG was found to have the highest regression coefficient which could be interpreted as the highest effect among the independent variables under investigation. VWG is one of the most widely used improvers in whole grain breads (Tebben et al., 2018). It is used to compensate for the loss in gluten network arisen from the inclusion of outer bran layers with almost no gluten forming proteins (Rosell and Gómez, 2007; Tebben et al., 2018). Inclusion of VWG was reported by many studies to have an improving dough mixing properties, and thus results in more gas retention and therefore higher bread volume and specific volume (Ortolan and Steel, 2017; Pojic' et al., 2017). The other two variables (i.e AA and SSL) had also positive effects on bread quality but to a lesser extent. The same findings were observed in case of overall acceptability scores of barley breads which were also found 
to be directly related to the addition level of the aforementioned independent variables. The coefficients of the effects of independent variables could be arranged in a descending order as follows: VWG, AA and then SSL which reflects higher effects of VWG on bread overall acceptability. These results are in accordance with several studies about the effects of AA and SSL on bread quality. Oxidation of free sulfhydryl groups on gluten proteins to form disulfide air bubbles during the fermentation and oven-spring processes, and this lead by its turn to bread loaves with higher volume and specific volumes (Tebben et al., 2018). Moreover, SSL was found to produce breads with softer and more uniform crumbs as previously reported by Armero and Collar (1996) which leads by its turn to higher overall sensory acceptability.

\subsubsection{Interactive effects of $V W G, A A$ and SSL on bread quality:}

The response surfaces of the interactive effects of VWG, AA and SSL on barley bread quality are illustrated in Fig.2. As observed from the regression analysis of the quadratic models, specific volume of barley bread was inversely affected by both VWGAA and AA-SSL interactions. However, such interactions had very low coefficients $(-0.03$ and -0.05 , respectively) which is comprehended as lower effects on bread specific volume. Silva et al., (2016) concluded that using AA in the presence of VWG might prevent any noticeable effects on whole grain breads as the original volume of bread was high due to the addition of VWG. Moreover, over oxidation due to high levels of AA was found to cause loss in oven rise and corresponding decreases in bread quality (Yamada and Preston, 1992). The same aforementioned slight interactive change was also noticed in case of VWG-SSL but in a desired positive manner. On the other hand, the effects of the interaction of the independent variables on barley bread overall acceptability was more observed with higher positive coefficients in case of VWG-AA and AA- SSL interactions, while was negative in case of VWG-SSL one. This corresponds to that VWG-AA, and AA-SSL together had an improving effect on barley bread overall acceptability probably to the increase in bread specific volume and softer, open bread crumb which is highly desirable by the panelists (Heiniö et al., 2016).

\subsubsection{Optimization process:}

In order to determine the levels of VWG, AA and SSL to produce whole grain barley bread with the best quality characteristics, optimization process on the selected quadratic models was performed by using Design-Expert7® Software. The optimization process targets for the independent variables (i.e. VWG, AA and SSL) were set to be "within range", while the dependent (response) targets were set to be "within range" in case of specific volume and to be "maximum" in case of overall acceptability. The results of the optimization process showed that the best addition levels of the different variables were: $9 \%, 84 \mathrm{ppm}$ and $0.2 \%$ of VWG, AA and SSL on flour weight basis, respectively (data not shown). These levels will be further used to produce the optimized whole grain barley bread formula which will be assessed in the next Phase (\#II) of this work.

The optimal addition level of VWG in this study $(9 \%)$ is higher than that obtained in the study carried out by Pojic' et al. (2017) that was $(2 \%)$. This might be attributed to two reasons; first, the study of Pojic' et al. (2017) included the addition of pregelatinized OSA starch which itself provides textural properties and has pronounced effects on bread volume 
Table 1. Box-Behnken experimental design of the combined effect of VWG, AA, and SSL on overall acceptability of whole grain barley bread.*

\begin{tabular}{|c|c|c|c|c|c|c|}
\hline \multirow[b]{2}{*}{ Run \# } & \multicolumn{3}{|c|}{ Coded values } & \multicolumn{3}{|c|}{ Actual values } \\
\hline & VWG & $\mathrm{AA}$ & SSL & $\begin{array}{l}\text { VWG } \\
\text { (g) }\end{array}$ & $\begin{array}{l}\mathrm{AA} \\
(\mathrm{ppm})\end{array}$ & $\begin{array}{l}\text { SSL } \\
(\mathrm{g})\end{array}$ \\
\hline 01 & -1 & 1 & 0 & 0 & 100 & 0.5 \\
\hline 02 & -1 & -1 & 0 & 0 & 0 & 0.5 \\
\hline 03 & 0 & 1 & 1 & 6 & 100 & 1 \\
\hline 04 & 1 & -1 & 0 & 12 & 0 & 0.5 \\
\hline 05 & 0 & -1 & 1 & 6 & 0 & 1 \\
\hline $06 * *$ & 0 & 0 & 0 & 6 & 50 & 0.5 \\
\hline 07 & -1 & 0 & -1 & 0 & 50 & 0 \\
\hline 08 & 1 & 0 & 1 & 12 & 50 & 1 \\
\hline 09 & 1 & 1 & 0 & 12 & 100 & 0.5 \\
\hline 10 & 0 & -1 & -1 & 6 & 0 & 0 \\
\hline 11 & 0 & 1 & -1 & 6 & 100 & 0 \\
\hline $12 * *$ & 0 & 0 & 0 & 6 & 50 & 0.5 \\
\hline 13 & -1 & 0 & 1 & 0 & 50 & 1 \\
\hline $14 * *$ & 0 & 0 & 0 & 6 & 50 & 0.5 \\
\hline 15 & 1 & 0 & -1 & 12 & 50 & 0 \\
\hline
\end{tabular}

*VWG : vital wheat gluten , AA= Ascorbic acid , SSL= sodium stearoyl-2-lactylate.

** Center points.

Table 2. Whole grain pan bread formulas (as for $100 \mathrm{~g}$ flour).

\begin{tabular}{lcccc}
\hline \multicolumn{1}{c}{ Ingredients* } & Unit & $\begin{array}{c}\text { Whole grain } \\
\text { wheat bread } \\
\text { (Control 1) }\end{array}$ & $\begin{array}{c}\text { Whole grain } \\
\text { barley bread } \\
\text { (Control 2) }\end{array}$ & $\begin{array}{c}\text { Optimized Whole } \\
\text { grain barley bread }\end{array}$ \\
\hline Whole grain Wheat flour & $\mathrm{g}$ & 100 & - & - \\
Whole grain barley flour & $\mathrm{g}$ & - & 100 & 90.8 \\
Shortening & $\mathrm{g}$ & 4 & 4 & 4 \\
Sugar & $\mathrm{g}$ & 5 & 5 & 5 \\
Skim milk powder & $\mathrm{g}$ & 2 & 2 & 2 \\
Salt & $\mathrm{g}$ & 1 & 1 & 1 \\
Instant active dry yeast & $\mathrm{g}$ & 2 & 2 & 2 \\
Water & $\mathrm{ml}$ & 65 & 65 & 65 \\
VWG & $\mathrm{g}$ & - & - & $94^{* *}$ \\
AA & $\mathrm{ppm}$ & - & - & $0.2^{* * *}$ \\
SSL & $\mathrm{g}$ & - & - & 2 \\
\hline
\end{tabular}

* VWG : vital wheat gluten, $\mathrm{AA}=$ ascorbic acid, $\mathrm{SSL}=$ sodium stearoyl-2-lactylate.

** Values were selected by the optimization proces 
and improved crumb properties to barley dough, and thus lower the levels of VWG needed in their study, and second due to the difference in VWG qualities previously reported by Ortolan and Steel (2017).

On the other hand, the optimal concentration of AA that was used in this study $(84 \mathrm{ppm})$ is relatively higher than those used in regular bread production (50-70 ppm as reported by Codină, 2008), this can be a result of the presence of natural antioxidant materials such as polyphenols in bran layers in whole grain flours which may counteract the effect of AA as an oxidizing agent, and thus required the addition of higher amounts of AA (Sahi et al., 2014; Tebben et al., 2018).

\subsection{Rheological properties of whole grain bread doughs:}

The rheological properties of optimized whole grain barley bread flour doughs as resulted from farinograph and extensograph tests are shown in Table 5. Farinograph is a device used for measuring the shear and viscosity of a flour doughs. In general, and as can be seen from the results, whole grain barley flour doughs had higher water absorption (which is measured from the farinograph burette) than the whole grain wheat one. This can be a result of the higher fiber content of whole grain barley than wheat flours (15.9 and 10.6\%, respectively, data not shown), with high tendency to hold water of barley flours in general when compared with wheat one (Skendi et al., 2010; Koletta et al., 2014; Sheikholeslami et al., 2018).

Optimized formula flour and wheat flours showed much higher stability times during mixing while this time was very low in case of barley flour alone. This can be attributed to the presence of continuous gluten network (whether naturally present in case of wheat dough, or added to optimized dough formula) which increased the stability and duration of the curve on the 500 B.U. line and reflected strong gluten networks. Moreover, the presence of the emulsifier SSL might has a role in increasing the stability of optimized dough as previously observed by Gómez et al., (2004) as they referred this phenomenon to the formation of a complex between SSL and the gluten proteins. On the other hand, the absence of such network resulted in a weak kneading properties and a rapid collapse in the dough viscoelastic characteristics (Ortolan and Steel, 2017; Tebben et al., 2018). Contrary to that trend, the degree of softening was significantly higher in case of barley flour dough when compared to both wheat or optimized flour doughs. This could be explained also by the absence of a continuous gluten network (Baik and Ullrich, 2008).

Extensograph is another important rheological device that is used to assess the stretching behavior of doughs and flour quality as well. It provides us with an indication about doughs expansion during fermentation, proofing and baking, and thus the quality of resulted bread. Extensibility, which represents the distance of dough stretching before being cut, was found to be higher in both wheat and optimized barley breads, while the value was low for barley bread as it showed less stretching ability and was cut immediately. Elasticity, which is the maximum resistance to extension, or the force that oppose the stretching of the dough was found to be lower in case of wheat dough than those of barley dough. This might be attributed to the stiffer barley doughs due to the presence of B-glucan with its high affinity to water which compete with protein and starch resulting in stiffer doughs (Skendi et al., 2010). For energy attribute, the higher value was demonstrated by wheat dough followed 
by optimized barley bread and finally the barley one. In addition to the effect of added VWG on forming dough with viscoelastic properties that are closer to that of wheat one, the effect of emulsifier also cannot be neglected as it is likely due to the ability of emulsifiers to form a laminar structure in the protein-starch interface. This structure by its turn improves the ability, uniformity and continuity of the formed gluten network to hold the other components of dough (Stampfli and Nersten, 1995).

\subsection{Proximate chemical composition and mineral content of whole grain breads:}

Proximate chemical composition and minerals contents of optimized whole grain barley bread as compared to its wheat and barley counterparts are shown in Table 6. No significant differences were observed between the tested breads with regard to moisture and ether extract. Protein content of the optimized barley bread was found to be significantly higher than the other two tested breads. As can be seen from the table, the protein content of optimized whole grain barley bread was $40 \%$ higher than that of its wheat counterpart. This can be attributed to the addition of vital wheat gluten (with a rate of $9 \%$ fwb) to the optimized barley bread formula. Dietary fiber contents in both barley breads were higher than that of wheat bread which can be explained by the higher content of whole grain barley flour when compared to wheat one. Similar or closer results about the chemical constituents of barley was previously reported by Oscarsson et al., (1996), and Newman and Newman (2006). At the same time, both barley breads were not significantly different in ash content than that of wheat with values ranged from 1.27 to $1.36 \%$. For mineral content, results showed that whole grain barley breads had significantly $(\mathrm{p} \leq 0.05)$ higher contents of calcium, phosphorus, magnesium and potassium, while no significant differences were found in case of iron and sodium. These results are consistent with the ranges reported by Newman and Newman (2006) concerning the mineral content of different barley varieties.

Percentage of nutritional goals (RDA, AI or UL) of minerals provided by $100 \mathrm{~g}$ of tested breads for middle-age persons (31-50 years old) is shown in Fig.3. The obtained optimized barley bread was found to provide with more than one fourth of the daily needs of phosphorus, iron (males), zinc and copper (with percentages of $35.4,35.0,27.3$ and $31.1 \%$, respectively). The percentage of iron provided for females is relatively limited (15.6\% of daily needs) due to the fact that females in this age range have higher needs for iron (USDA, 2015). Other minerals like calcium, magnesium and potassium will be needed to be provided by other food sources in the daily diet (USDA, 2015).

\subsection{Physical, textural and crumb DIA properties of whole grain breads:}

Barley flour lacks the presence of high quality gluten-forming proteins, and thus results in breads with inferior physical, textural and crumb properties as compared to wheat flour (Table 7). As shown, bread made from whole grain flour exhibits better bread volume (Fig.4), textural properties and crumb characteristics when compared to barley one. In the present work, and in order to overcome this issue, VWG was added along with AA and SSL to include a continuous and improved gluten network into barley bread formulas. Although volume, weight and specific volume of optimized barley bread were lower than the wheat one, it demonstrated a significantly $(\mathrm{p}<0.05)$ enhanced volume and specific volume against barley bread. 
Table 3. Summary ANOVA and model types for the effects of VWG, AA and SSL on specific volume and overall acceptability of whole grain breads*.

Summary ANOVA $\quad$ Model Type

\begin{tabular}{|c|c|c|c|c|c|c|c|c|c|c|}
\hline & \multirow{2}{*}{\multicolumn{2}{|c|}{$\begin{array}{cc}\text { Min. } & \text { Max. } \\
\text { value } & \text { value }\end{array}$}} & \multirow[b]{2}{*}{ Mean } & & & & & \\
\hline & & & & F Value & $\begin{array}{l}\text { P-Value } \\
\text { Prob.>F }\end{array}$ & Significance & Type & $\mathrm{R}^{2}$ & $\begin{array}{c}\text { Adjusted } \\
\mathrm{R}^{2}\end{array}$ & $\begin{array}{l}\text { Adequate } \\
\text { Precision }\end{array}$ \\
\hline Specific volume & 1.7 & 2.6 & 2.17 & 7.64 & 0.019 & Significant & Quadratic & 0.93 & 0.81 & 7.81 \\
\hline Overall acceptability & 4 & 8 & 6.13 & 12.65 & 0.006 & Significant & Quadratic & 0.96 & 0.88 & 9.51 \\
\hline
\end{tabular}

* VWG= vital wheat gluten, $\mathrm{AA}=$ Ascorbic acid, $\mathrm{SSL}=$ sodium stearoyl-2-lactylate.

Table 4. Model regression coefficients for the effects of VWG, AA and SSL on specific volume and overall acceptability of whole grain breads*,**.

Model regression coefficients**

\begin{tabular}{|c|c|c|c|c|c|c|c|c|c|c|}
\hline & \multicolumn{10}{|c|}{ Model regression coefficients** } \\
\hline & Intercept & A & $\mathrm{B}$ & $\mathrm{C}$ & $\mathrm{AB}$ & $\mathrm{AC}$ & $\mathrm{BC}$ & $A^{2}$ & $\mathrm{~B}^{2}$ & $\mathrm{C}^{2}$ \\
\hline Specific volume & 2.37 & 0.24 & 0.01 & 0.08 & -0.03 & 0.05 & -0.05 & -0.45 & 0.05 & 0.03 \\
\hline Overall acceptability & 7.33 & 1.00 & 0.50 & 0.25 & 0.50 & -0.50 & 0.00 & -1.92 & -0.42 & 0.08 \\
\hline
\end{tabular}

* VWG= vital wheat gluten, $\mathrm{AA}=$ Ascorbic acid, $\mathrm{SSL}=$ sodium stearoyl-2-lactylate.

** A, B, C = coded values for VWG, AA, and SSL, respectively 

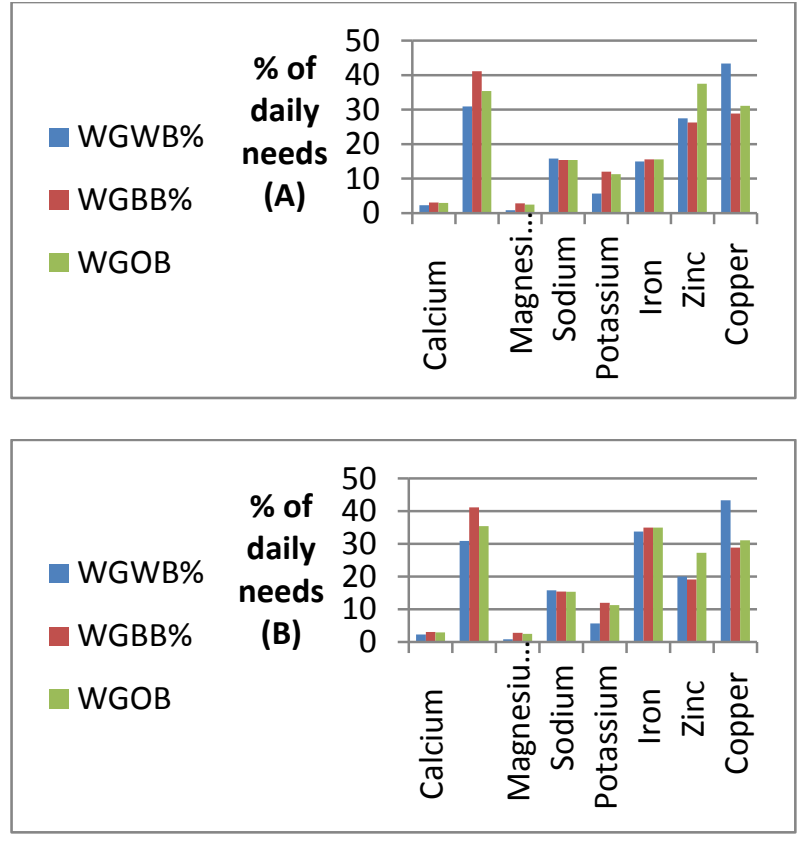

Fig. 3. Percentage of nutritional goals of minerals provided by $100 \mathrm{~g}$ of whole-grain wheat, barley and optimized barley breads*.

In addition to the individual effects of VWG, AA and SSL on bread volume, the interactive effect VWG-SSL was shown to have an improving effect on bread volume as previously shown in Table 4 . The addition of VWG provides strength, elasticity and enhanced gas retention to the bread dough as described by Tebben et al. (2018). This by its turn increases the ability of dough to withstand the expansion without being ruptured in both proofing and baking steps of bread processing, causing an increase in bread volume and specific volume. These results are also supported by the increased extensibility of gluten-containing bread formulas (Ortolan and Steel, 2017) as discussed in Table 5. Moreover, the addition of SSL was found to significantly increase whole grain bread volume made either by straight, or sponge and dough methods than did the other tested ingredients in the study including even ascorbic acid (Indrani \& Rao, 1992). Ascorbic acid in its interactive effect (VWG-AA and AA-SSL) was found to have a slight negative impact on bread volume. This can be explained that higher doses of AA resulted in exhaustion of the SH-reactive groups (Codină, 2008).

Water activity (aw) of both barley breads was found to be slightly higher than that of wheat bread (Table 7). This might be a result of the higher fiber content of barley breads as previously shown in Table 6 . The same observation was reported by Park et al., (1997). For the TPA analysis, both wheat and optimized barley breads were less hard than the barley one. Contrary to that, barley bread was lower in cohesiveness and springiness than other breads. Hardness is defined as the force required to compress a food between the molars or as the force necessary to attain a given deformation. It was found to be negatively correlated with higher bread specific volume, which is a result of the inclusion of more air bubbles into bread crumb, and thus requires less force to compress bread slices. On the other hand, the key parameters of cohesiveness and springiness reflect the development and formation of internal bonding within bread structure. Cohesiveness is known as a measurement of how well structure of a product withstands compression, while springiness is simply the ability to regain original shape after pressing down the crumb. 


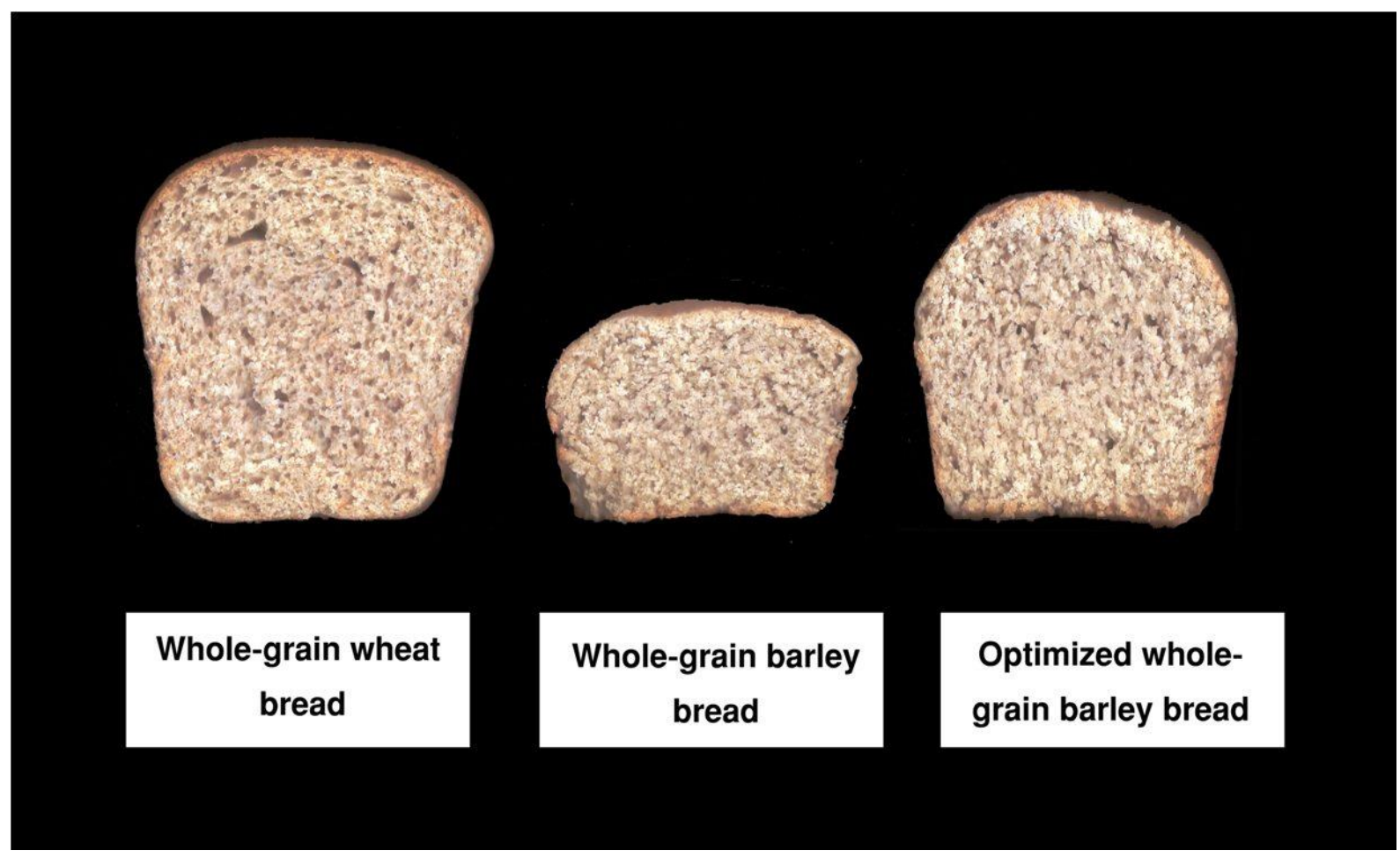

Fig. 4. Cross-sections of whole-grain wheat, barley and optimized barley formula breads. Table 5. Rheological properties of whole grain bread doughs*, **.

$\begin{array}{ccc}\text { Whole grain } & \text { Whole grain } & \text { Optimized Whole } \\ \text { wheat bread } & \text { barley bread } & \text { grain barley } \\ \text { (Control 1) } & \text { (Control 2) } & \text { bread }\end{array}$

\section{Farinograph parameters:}

$\begin{array}{llll}\text { Water Absorption (\%) } & 66.3^{\mathrm{b}} \pm 0.20 & 69.2^{\mathrm{a}} \pm 0.35 & 69.40^{\mathrm{a}} \pm 0.10 \\ \text { Arrival time (min.) } & 1.25^{\mathrm{b}} \pm 0.25 & 1.75^{\mathrm{a}} \pm 0.25 & 1.25^{\mathrm{b}} \pm 0.025 \\ \text { Development time (min.) } & 2.0^{\mathrm{a}} \pm 0.00 & 2.0^{\mathrm{a}} \pm 0.00 & 2.0^{\mathrm{a}} \pm 0.00 \\ \text { Dough stability (min.) } & 12.5^{\mathrm{b}} \pm 0.50 & 0.75^{\mathrm{c}} \pm 0.25 & 13.75^{\mathrm{a}} \pm 0.75 \\ \text { Degree of softening (B.U.) } & 40.0^{\mathrm{b}} \pm 0.0 & 110^{\mathrm{a}} \pm 10.00 & 30^{\mathrm{b}} \pm 10.00\end{array}$

\section{Extensograph parameters:}

$\begin{array}{llll}\text { Elasticity "R" (BU) } & 170^{\mathrm{c}} \pm 10.0 & 225^{\mathrm{b}} \pm 0.5 & 245^{\mathrm{a}} \pm 5.0 \\ \text { Extensibility "E" }(\mathrm{mm}) & 82.5^{\mathrm{a}} \pm 2.5 & 40.0^{\mathrm{c}} \pm 5.0 & 60.0^{\mathrm{b}} \pm 5.0 \\ \text { Proportional number (R/E) } & 2.05^{\mathrm{c}} \pm 0.06 & 5.73^{\mathrm{a}} \pm 0.84 & 4.11^{\mathrm{b}} \pm 0.41 \\ \text { Energy }\left(\mathrm{cm}^{2}\right) & 27.5^{\mathrm{a}} \pm 2.50 & 15.0^{\mathrm{c}} \pm 0.0 & 22.5^{\mathrm{b}} \pm 2.5\end{array}$

* Means within the same row with the same letters are not significantly different $(p \leq 0.05), n=2$. ** Values are expressed as means \pm standard deviation. 
These results are similar to those obtained by Carocho et al. (2020) who reported that wholemeal wheat bread was less hard while had higher springiness and cohesiveness than their non-gluten-forming grains counterpart breads (rye and oat). Closer observations were also reported by Pojic' et al. (2017) with regard to the production of pure barley bread. They attributed the significant changes in crumb hardness and cohesiveness to the formation of gluten network as a result of VWG addition, and hence the higher bread specific volume as mentioned before. DIA of tested bread crumb samples showed an increase in crumb cell count (number of cells per $\mathrm{cm} 2$ ) of wheat bread up to a double of that in barley breads (Table 7). On contrast, average cell size was lower in wheat bread than in barley bread. The standard deviation of average cell size was lower in wheat bread which can be interpreted as lower variations and more uniform cell sizes when compared to barley counterparts. These differences between bread samples could be attributed to the differences in dough strength associated with the presence of wheat gluten, which is also supported by the rheological measurements in Table 5. The absence of gluten network in barley bread led to the production of weak doughs, in which small air bubbles tended to coalesce into larger ones and consequently lower cell numbers and bigger gas cells are formed (Sapirstein et al., 1994).

Table 6. Proximate chemical composition and mineral content (as-is basis) of whole grain breads.*,**

Whole grain wheat bread

(Control 1)
Whole grain barley bread (Control 2)
Optimized Whole grain barley bread

\begin{tabular}{llll}
\hline Moisture (\%) & $34.50^{\mathrm{a}} \pm 0.08$ & $37.24^{\mathrm{a}} \pm 0.44$ & $37.04^{\mathrm{a}} \pm 0.07$ \\
Protein (\%) & $9.95^{\mathrm{c}} \pm 0.03$ & $10.61^{\mathrm{b}} \pm 0.14$ & $13.96^{\mathrm{a}} \pm 0.09$ \\
Ether extract (\%) & $1.98^{\mathrm{a}} \pm 0.02$ & $2.04^{\mathrm{a}} \pm 0.02$ & $2.04^{\mathrm{a}} \pm 0.06$ \\
Dietary fiber, total (\%) & $6.08^{\mathrm{b}} \pm 0.08$ & $9.26^{\mathrm{a}} \pm 0.58$ & $8.16^{\mathrm{a}} \pm 0.06$ \\
Ash (\%) & $1.31^{\mathrm{ab}} \pm 0.03$ & $1.36^{\mathrm{a}} \pm 0.04$ & $1.27^{\mathrm{b}} \pm 0.02$ \\
NFE (\%) & $46.18^{\mathrm{a}} \pm 0.06$ & $39.9^{\mathrm{b}} \pm 0.08$ & $37.53^{\mathrm{c}} \pm 0.28$ \\
\hline $\mathrm{Ca}(\mathrm{mg} / 100 \mathrm{~g})$ & $22.8^{\mathrm{c}} \pm 0.6$ & $31.0^{\mathrm{a}} \pm 1.0$ & $29.4^{\mathrm{b}} \pm 0.6$ \\
$\mathrm{P}(\mathrm{mg} / 100 \mathrm{~g})$ & $216.3^{\mathrm{c}} \pm 3.3$ & $287.9^{\mathrm{a}} \pm 6.9$ & $247.8^{\mathrm{b}} \pm 7.6$ \\
$\mathrm{Mg}(\mathrm{mg} / 100 \mathrm{~g})$ & $2.6^{\mathrm{c}} \pm 0.0$ & $9.1^{\mathrm{a}} \pm 0.0$ & $8.0^{\mathrm{b}} \pm 0.0$ \\
$\mathrm{Na}(\mathrm{mg} / 100 \mathrm{~g})$ & $364.1^{\mathrm{a}} \pm 14.0$ & $354.5^{\mathrm{a}} \pm 14.5$ & $354.0^{\mathrm{a}} \pm 4.0$ \\
$\mathrm{~K}(\mathrm{mg} / 100 \mathrm{~g})$ & $266.2^{\mathrm{c}} \pm 0.7$ & $564.5^{\mathrm{a}} \pm 4.9$ & $531.0^{\mathrm{b}} \pm 19.0$ \\
$\mathrm{Fe}(\mathrm{mg} / 100 \mathrm{~g})$ & $2.7^{\mathrm{a}} \pm 0.0$ & $2.8^{\mathrm{a}} \pm 0.1$ & $2.8^{\mathrm{a}} \pm 0.1$ \\
$\mathrm{Zn}(\mathrm{mg} / 100 \mathrm{~g})$ & $2.2^{\mathrm{b}} \pm 0.2$ & $2.1^{\mathrm{b}} \pm 0.0$ & $3.0^{\mathrm{a}} \pm 0.3$ \\
$\mathrm{Cu}(\mathrm{mg} / 100 \mathrm{~g})$ & $0.39^{\mathrm{a}} \pm 0.0$ & $0.26^{\mathrm{b}} \pm 0.1$ & $0.28^{\mathrm{b}} \pm 0.0$
\end{tabular}

* Means within the same row with the same letters are not significantly different $(p \leq 0.05), n=3$. ** Values are expressed as means \pm standard deviation. 
Table 7. Physical, textural and crumb DIA properties of whole grain breads.

\begin{tabular}{|c|c|c|c|}
\hline & $\begin{array}{l}\text { Whole grain } \\
\text { wheat bread } \\
\text { (Control 1) }\end{array}$ & $\begin{array}{l}\text { Whole grain } \\
\text { barley bread } \\
\text { (Control 2) }\end{array}$ & $\begin{array}{c}\text { Optimized Whole } \\
\text { grain barley } \\
\text { bread }\end{array}$ \\
\hline Volume $\left(\mathrm{cm}^{3}\right)$ & $379.0^{\mathrm{a}} \pm 1.0$ & $227.0^{c} \pm 2.0$ & $313.0^{\mathrm{b}} \pm 7.0$ \\
\hline Weight (g) & $142.9^{a} \pm 0.8$ & $135.4^{\mathrm{b}} \pm 0.0$ & $139.6^{\mathrm{a}} \pm 1.1$ \\
\hline Specific volume $\left(\mathrm{cm}^{3} / \mathrm{g}\right)$ & $2.65^{\mathrm{a}} \pm 0.02$ & $1.64^{c} \pm 0.02$ & $2.24^{\mathrm{b}} \pm 0.06$ \\
\hline Water activity $\left(\mathrm{a}_{\mathrm{w}}\right)$ & $0.882^{\mathrm{b}} \pm 0.0$ & $0.893^{\mathrm{a}} \pm 0.0$ & $0.891^{\mathrm{a}} \pm 0.0$ \\
\hline Hardness (N) & $16.86^{c} \pm 0.9$ & $32.76^{\mathrm{a}} \pm 1.1$ & $25.25^{\mathrm{b}} \pm 2.2$ \\
\hline Adhesiveness (mJ) & $0.4^{\mathrm{ab}} \pm 0.0$ & $0.2^{\mathrm{b}} \pm 0.0$ & $0.9^{\mathrm{a}} \pm 0.5$ \\
\hline Cohesiveness & $0.5^{\mathrm{a}} \pm 0.0$ & $0.2^{\mathrm{c}} \pm 0.0$ & $0.3^{\mathrm{b}} \pm 0.0$ \\
\hline Springiness (mm) & $5.41^{\mathrm{a}} \pm 0.3$ & $3.94^{\mathrm{c}} \pm 0.0$ & $4.92^{\mathrm{b}} \pm 0.0$ \\
\hline Cell count $\left(\mathrm{cell} / \mathrm{cm}^{2}\right.$ ) & $151^{\mathrm{a}} \pm 27$ & $68^{b} \pm 33$ & $72^{\mathrm{b}} \pm 8$ \\
\hline Average cell size $\left(\mathrm{mm}^{2}\right)$ & $9.53^{\mathrm{b}} \pm 0.37$ & $20.81^{\mathrm{a}} \pm 3.8$ & $20.1^{\mathrm{a}} \pm 1.5$ \\
\hline SD for cell areas & $103.64^{\mathrm{a}} \pm 10.91$ & $118.40^{\mathrm{a}} \pm 14.63$ & $177.21^{\mathrm{a}} \pm 58.68$ \\
\hline
\end{tabular}

* Means within the same row with the same letters are not significantly different $(\mathrm{p} \leq 0.05), \mathrm{n}=3$.

$* *$ Values are expressed as means \pm standard deviation.

Table 8. Sensory scores for whole grain breads. $* * *$

$\begin{array}{ccc}\begin{array}{c}\text { Whole grain wheat } \\ \text { bread }\end{array} & \begin{array}{c}\text { Whole grain barley } \\ \text { bread }\end{array} & \begin{array}{c}\text { Optimized Whole } \\ \text { (Control 1) }\end{array} \\ \text { (Control 2) } & \text { grain barley bread }\end{array}$

\begin{tabular}{lccc}
\hline Appearance (9) & $8.3^{\mathrm{a}} \pm 0.82$ & $4.8^{\mathrm{c}} \pm 0.63$ & $7.2^{\mathrm{b}} \pm 0.42$ \\
Texture (9) & $8.6^{\mathrm{a}} \pm 0.51$ & $4.6^{\mathrm{c}} \pm 0.51$ & $6.7^{\mathrm{b}} \pm 0.48$ \\
Crumb color (9) & $8.5^{\mathrm{a}} \pm 0.71$ & $7.7^{\mathrm{b}} \pm 0.48$ & $7.4^{\mathrm{b}} \pm 0.84$ \\
Flavor (9) & $8.6^{\mathrm{a}} \pm 0.52$ & $7.0^{\mathrm{b}} \pm 0.47$ & $7.6^{\mathrm{b}} \pm 1.07$ \\
Overall acceptability (9) & $8.7^{\mathrm{a}} \pm 0.48$ & $5.7^{\mathrm{c}} \pm 0.48$ & $7.1^{\mathrm{b}} \pm 0.57$
\end{tabular}

* Means within the same row with the same letters are not significantly different $(\mathrm{p} \leq 0.05), \mathrm{n}=10$.

$* *$ scores are expressed as means \pm standard deviation 


\subsection{Sensory characteristics of whole grain breads:}

A comparison between different tested breads with respect to sensory attributes (i.e. appearance, texture, crumb color, flavor and overall acceptability) is shown in Table 8 . As seen, wheat bread has achieved the highest score for all sensory attributes. Optimized barley bread exhibited significantly higher $(\mathrm{p}<0.05)$ appearance score and texture characteristics than the regular barley one. Appearance of bread is an important quality attribute that includes different descriptors such as bread volume, cross-section symmetry, and crust and crumb characteristics. As wheat bread achieved the highest bread volume with more uniform crumb structure and cell distribution, it had the highest appearance score followed by the and SSL has shown relatively higher texture scores than (no-additive) barley one. In addition to the role of VWG in improving the textural properties of bread, SSL also has a potential to be involved in the softer crumb texture as previously described by Tebben et al. (2018). In respect to crumb color and flavor, both barley breads were significantly lower than those of wheat one. The lower color score is attributed to the development of dark grayish color that is a characteristic of barley flour products as described by Baik (2016). Moreover, bitter taste and the presence of unfamiliar off-flavors affected negatively the flavor scores of both barley breads. This is attributed to condensed tannins proanthocyanidin (PAs) and phenolic acids present in whole grain barley flours, which are responsible for the bitter and astringent taste (Lesschaeve \& Noble, 2005). However, overall acceptability score of optimized barley bread (which corresponded to "like moderately "on the 9-points hedonic liking scale) was lower than that of wheat bread optimized barley bread. Inclusion of VWG and SSL into the optimized barley bread formula improved the quality of bread. Anyhow, optimized barley bread had a flatter shape which contributed also to reduce the sensory score for appearance as previously described by Škrbić et al.(2009). In addition, Sensory characteristics of bread texture correlated with the instrumentally measured texture by TPA (Table 7). Panelists reported that wheat bread had the highest textural properties including less hardness, crumb compressibility, softness and chewing characteristics. The opposite trend was observed in case of barley bread. However, optimized barley bread with added VWG, AA

(which corresponded to "extremely like/like very much ").but was still acceptable by the panelists.

\section{Conclusions}

In the present study, the three additives under investigation (i.e. VWG, AA and SSL) were found to have different effects on whole grain barley bread quality to variable extents. It is well known that the production of leavened bread from barley flour is a key challenge as barley flour lacks the proteins necessary to produce viscoelastic and continuous gluten network, which hinder by its turn the production of good quality bread. Most of the effects of the studied additives, from both individual and interactive terms, were towards the production of improved whole grain barley bread with enhanced specific volume and overall sensory acceptability. However, inclusion of VWG contributed in structuring a gluten network in barley bread and the production of enhanced bread. Moreover, SSL was associated with more uniform and softer 
crumb properties. When optimization process was conducted to determine the best amounts of the aforementioned additives to be added to the barley bread formula, the produced optimized whole grain bread was comparable to its wheat counterpart. Higher fiber, protein and mineral contents were the distinctive characteristics of the produced optimized bread. However, the real contribution of these nutrients to the daily nutritional needs is dependent on their bioavailability, and further studies are needed in this regard. In addition, more efforts are needed to improve the acceptability and awareness of consumers towards the nutritional benefits of barley bread and barley products in general. More studies are needed in the area of using pure whole grain barley in the production of other bakery products and ways to improve their quality characteristics with a focus on their technological, nutritional, and sensory quality.

\section{Acknowledgment}

The author would like to thank Mr. Mostafa Abdelmotaleb, technical baker at Food Technology Research Institute (FTRI) for his assistance in bread baking experiments.

\section{CONFLICT OF INTEREST}

The author declares that he doesn't have any conflict of interest.

\section{References}

AACC (2010)'Approved Methods of Analysis of AACC International' St. Paul, MNY. USA.

Al-Attabi, Z. H., Merghani, T. M., Ali, A., and Rahman, M. S. (2017)' Effect of barley flour addition on the physico-chemical properties of dough and structure of bread' Journal of Cereal Science, 75, pp. 61-68.
Anderson, M.J and Whitcomb, P.J. (2017) 'RSM simplified: optimizing process using response surface methods for design of experiments' 2nd edition. CRC Press, Taylor \& Francis Crou. LLC. Boca Raton, FL.

Angioloni, A., and Collar, C. (2009) 'Bread crumb quality assessment: a plural physical approach' European Food Research and Technology, 229(1), pp. 21 30.

Armero, E., and Collar, C. (1996) 'Antistaling additive effects on fresh wheat bread quality/Efectos de los aditivos antienvejecimiento sobre la calidad del pan fresco' Food Science and Technology International, 2(5), pp. 323-333.

Baik, B. K., and Ullrich, S. E. (2008) 'Barley for food: characteristics, improvement, and renewed interest' Journal of cereal science, 48(2), pp.233-242.

Baik, B. K. (2016) 'Current and potential barley grain food products' Cereal Foods World, 61(5), pp.188-196.

Carocho, M., Morales, P., Ciudad-Mulero, M., Fernandez-Ruiz, V., Ferreira, E., Heleno, S., Rodrigues, P, Barros, L. and Ferreira, I. C. (2020) 'Comparison of different bread types: Chemical and physical parameters' Food Chemistry, 310, 125954 (in press).

Carter, A. Y., Hawes, M. C., and Ottman, M. J. (2019) 'Drought-Tolerant Barley: I. Field Observations of Growth and Development' Agronomy, 9(221), pp. 118.

Codină, G. G. (2008) 'Effects of different doses of ascorbic acid on alveograph and bread making quality of wheat flour with average quality as starting material' Journal of Agroalimentary Processes and Technologies, 14, pp. 87-92.

Dhingra, S., and Jood, S. (2002) 'Organoleptic and nutritional evaluation of wheat breads 
supplemented with soybean and barley flour' Food chemistry, 77(4), pp.479-488.

Gómez, M., Del Real, S., Rosell, C. M., Ronda, F., Blanco, C. A., and Caballero, P. A. (2004) 'Functionality of different emulsifiers on the performance of breadmaking and wheat bread quality' European Food Research and Technology, 219(2), pp.145-150.

Heiniö, R. L., Noort, M. W. J., Katina, K., Alam, S. A., Sozer, N., De Kock, H. L., Hersleth, M. and Poutanen, K. (2016) 'Sensory characteristics of whole grain and bran-rich cereal foods-A review' Trends in Food Science \& Technology, 47, pp. 25-38.

Holtekjølen, A. K., Bævre, A. B., Rødbotten, M., Berg, H., and Knutsen, S. H. (2008). Antioxidant properties and sensory profiles of breads containing barley flour. Food chemistry, 110(2), 414-421.

Idehen, E., Tang, Y., and Sang, S. (2017) 'Bioactive phytochemicals in barley. Journal of food and drug analysis', 25(1), pp. 148-161.

Indrani, D. and Rao, G.V. (1992) 'Influence of Additives on the Rheological and Bread Making Characteristics of Differently Milled Whole Wheat Flours' Journal of Food Science and Technology, 29(5), pp. 296-298.

Kinner, M., Nitschko, S., Sommeregger, J., Petrasch, A., Linsberger-Martin, G., Grausgruber, H., Berghofer, E. and Siebenhandl-Ehn, S. (2011) 'Naked barley_optimized recipe for pure barley bread with sufficient beta-glucan according to the EFSA health claims' Journal of cereal science, 53(2), pp. 225230.

Koletta, P., Irakli, M., Papageorgiou, M., and Skendi, A. (2014) 'Physicochemical and technological properties of highly enriched wheat breads with whole grain non wheat flours' Journal of Cereal science, 60(3), pp. 561-568.

Langridge, P. (2018) 'Economic and academic importance of barley'. In N. Stein \& G. Muehlbauer, G. (Eds.) The barley genome compendium of plant genomes

Lesschaeve, I., and Noble, A. C. (2005) 'Polyphenols: factors influencing their sensory properties and their effects on food and beverage preferences' The American journal of clinical nutrition, 81(1), pp. 330S-335S.

Magdić, D., Horvat, D., Drezner, G., Jurković, Z., and Šimić, G. (2006) 'Image analysis of bread crumb structure in relation to gluten strength of wheat' Poljoprivreda (Agriculture), 12(1), pp. 58-62.

Malcolmson, L., Lukie, C., Swallow, K., Sturzenegger, T., and Han, J. (2014) 'Using barley flour to formulate foods to meet health claims' Cereal Foods World, 59(5), pp. 235-242.

Meilgaard, M.C, Civille, G.V. and Carr, B.T. (2016) 'Sensory evaluation techniques'. 5th edition. CRC Press, Taylor \& Francis Group, Boca Raton.

Newman, C. W., and Newman, R. K. (2006) 'A brief history of barley foods'. Cereal foods world, 51(1), pp. 4-7.

Newman, R.K. and Newman, C.W. (2008) 'Barley for food and health: science, technology and products'. John Wiley \& Sons, Inc., Hoboken, New Jersey.

Önning, G. (2007) 'Carbohydrates and risk of cardiovascular dieases'. In: C.C. Biliaderis \& M.S. Izydorczyk (Eds). 'Functional food carbohydrates'. CRC Press, Boca Raton, pp. 291-319.

Ortolan, F., and Steel, C. J. (2017) 'Protein characteristics that affect the quality of vital wheat gluten to be used in baking: A review' Comprehensive Reviews in Food Science and Food Safety, 16(3), pp. 369381. 
Oscarsson, M., Andersson, R., Salomonsson, A. C., and Åman, P. (1996) 'Chemical composition of barley samples focusing on dietary fibre components' Journal of cereal science, 24(2), pp. 161-170.

Ozbek, N., and Akman, S. (2016) 'Method development for the determination of calcium, copper, magnesium, manganese, iron, potassium, phosphorus and zinc in different types of breads by microwave induced plasma-atomic emission spectrometry'Food Chemistry, 200, pp. 245-248.

Park, H., Seib, P. A., and Chung, O. K. (1997) 'Fortifying bread with a mixture of wheat fiber and psyllium husk fiber plus three antioxidants' Cereal Chemistry, 74(3), pp. 207-211.

Parenti, O., Guerrini, L., Cavallini, B., Baldi, F., and Zanoni, B. (2020) 'Breadmaking with an old wholewheat flour: Optimization of ingredients to improve bread quality' LWT-Food Science and Technology, 121, 108980 (in press).

Pojić, M., Hadnađev, T. D., Hadnađev, M., Rakita, S., and Torbica, A. (2017) 'Optimization of additive content and their combination to improve the quality of pure barley bread' Journal of food science and technology, 54(3), pp. 579-590.

Rosell, C. M., and Gómez, M. (2007) 'Frozen dough and partially baked bread: an update' Food Reviews International, 23(3), pp. 303-319.

Sahi, S. S. (2014) 'Ascorbic acid and redox agents in bakery systems'. In: W. Zhau (ed.), Bakery products science and technology', 2nd edition. John Wiley \&Sons, UK. pp.183-197

Sapirstein, H. D., Roller, R., and Bushuk, W. (1994) 'Instrumental measurement of bread crumb grain by digital image analysis' Cereal Chemistry, 71(4), pp. 383-391.
SAS (1999) 'Statistical Analysis System User's Guide: Statistics' SAS Institute Inc., Cary, NC, USA.

Sheikholeslami, Z., Karimi, M., Komeili, H. R., and Mahfouzi, M. (2018) 'A new mixed bread formula with improved physicochemical properties by using hullless barley flour at the presence of guar gum and ascorbic acid' LWT-Food Science and Technology, 93, pp. 628-633.

Silva, C. B. D., Almeida, E. L., and Chang, Y. K. (2016) 'Interaction between xylanase, glucose oxidase and ascorbic acid on the technological quality of whole wheat bread' Ciência Rural, 46(12), pp. 22492256.

Skendi, A., Biliaderis, C. G., Papageorgiou, M., and Izydorczyk, M. S. (2010) 'Effects of two barley $\beta$-glucan isolates on wheat flour dough and bread properties' Food Chemistry, 119(3), pp. 1159-1167.

Škrbić, B., Milovac, S., Dodig, D., and Filipčev, B. (2009) 'Effects of hull-less barley flour and flakes on bread nutritional composition and sensory properties' Food Chemistry, 115(3), pp. 982-988.

Stampfli, L., \& Nersten, B. (1995) 'Emulsifiers in bread making' Food chemistry, 52(4), pp. 353-360.

Sullivan, P., O'Flaherty, J., Brunton, N., Arendt, E., and Gallagher, E. (2010) 'Fundamental rheological and textural properties of doughs and breads produced from milled pearled barley flour' European Food Research and Technology, 231(3), pp. 441-453.

Sullivan, P., Arendt, E., and Gallagher, E. (2013) 'The increasing use of barley and barley by-products in the production of healthier baked goods' Trends in Food Science \& Technology, 29(2), pp. 124134. 
Swanson, R. B., and Penfield, M. P. (1988) 'Barley flour level and salt level selection for a whole- grain bread formula' Journal of Food science, 53(3), pp. 896-901.

Tebben, L., Shen, Y., and Li, Y. (2018) 'Improvers and functional ingredients in whole wheat bread: A review of their effects on dough properties and bread quality' Trends in Food Science \& Technology, 81, pp. 10-24.

Teuber, R., Dolgopolova, I., and Nordström, J. (2016) 'Some like it organic, some like it purple and some like it ancient: Consumer preferences and WTP for value-added attributes in whole grain bread' Food Quality and Preference, 52, pp. 244-254.

Tricase, C., Amicarelli, V., Lamonaca, E. and Rana, R.L. (2018) 'Economic analysis of the barley market and related uses'. In $Z$. Tadele (ed.), 'Grasses as Food and Feed'. IntechOpen, Lower Thames st., London. pp. $25-46$

USDA (2015) 'Dietary guidelines for Americans: 2015-2020', 8th edition. U.S. Department of Health and Human Services and US. Department of Agriculture. Available at: http://health.gov/dietaryguidelines/2015.

USDA (2020) 'World Agricultural Production' Foreign Agricultural Service, United States Department of Agriculture, USA.

Yamada, Y., and Preston, K. R. (1992) 'Effects of individual oxidants on oven rise and bread properties of Canadian short process bread' Journal of Cereal Science, 15(3), pp. 237-251. 